\title{
EHMTI-0155. The course of headache in idiopathic intracranial hypertension: a 12 month prospective follow-up study
}

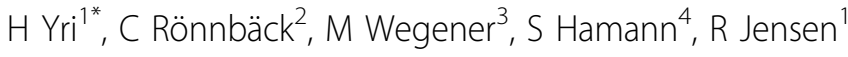 \\ From 4th European Headache and Migraine Trust International Congress: EHMTIC 2014 \\ Copenhagen, Denmark. 18-21 September 2014
}

\section{Background}

Although many patients with Idiopathic intracranial hypertension (IIH) experience disabling headache, data on the long-term outcome are sparse. Thus very little is known about predictors and mechanisms of chronification.

\section{Aims}

To prospectively describe the course of headache during the first year of IIH.

\section{Methods}

Patients with newly diagnosed IIH were consecutively included from December 2010 to June 2013. Treatment according to international guidelines was initiated at diagnosis. Headache history was based on diaries and standardized interviews performed at baseline and after 1, 2, 3 and 12 months. Intracranial pressure (ICP) was recorded at base line and after 3 months. Papilledema was assessed by optical coherence tomography (OCT) and compared to healthy controls.

\section{Results}

We included 44 patients, 35 completed the one-year follow-up. Dramatic headache improvement occurred within the first weeks after diagnosis and treatment. After one year 13 patients reported no headache. Fifteen of the remaining 22 patients reported sustained chronic headache. Episodic headache was reported by 7 patients. Early age of onset $(\mathrm{OR}=1.13, \mathrm{p}=0.03)$ and high ICP (and $\mathrm{OR}=0.86, \mathrm{p}=0.03$ ) were associated with positive headache outcome. Papilledema decreased rapidly within the first three months of diagnosis. After 12 months OCT measures had normalised.

\section{Conclusions}

Although headache responded very well in $43 \%$ of patients, sustained long-term headache was seen in the remaining patients, despite normalization of ICP and papilledema. Headache in IIH may thus be attributed to more complex mechanisms than ICP elevation alone. High ICP at baseline and young age predicted positive headache outcome.

Conflict of interest.

\section{Authors' details}

'Danish Headache Center, Neurology, Copenhagen, Denmark.

${ }^{2}$ Ophthalmology, Opthalmology, Copenhagen, Denmark.

${ }^{3}$ Neuro-ophthalmology, Opthalmology, Copenhagen, Denmark.

${ }^{4}$ Neuro-ophtalmology, Opthalmology, Copenhagen, Denmark.

Published: 18 September 2014

doi:10.1186/1129-2377-15-S1-C64

Cite this article as: Yri et al:: EHMTI-0155. The course of headache in

idiopathic intracranial hypertension: a 12 month prospective follow-up study. The Journal of Headache and Pain 2014 15(Suppl 1):C64. 